\section{First do no harm}

\section{AnneHardy}

\author{
Bad Medicine: D octors D oing H arm \\ Since Hippocrates \\ by $D$ avid Wootton \\ O xford U niversity Press, 0 xford, U K \\ 320 pp, \$25/£17 \\ ISBN 0192803557
}

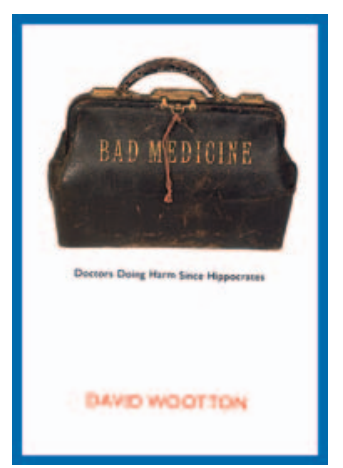

Bad Medicine: Doctors Doing Harm Since Hippocrates is a curious book. David Wootton presents a potted and unoriginal history of medicine from antiquity to the present, concentrating on

three principal themes: medicine was bad before 1860; the germ theory of disease transformed medicine; and the self-interest of doctors delayed medical progress. Wootton argues that medicine only became effective with the practical realization of Joseph Lister's germ theory in the 1860s, and highlights discoveries that could have opened up the world of effective medical therapy decades earlier, if only doctors had been enlightened enough to accept them.

According to Wootton, the jump into modern scientific medicine-defined as "constant improvements in therapy grounded in constantly developing scientific understanding" - should have followed Anton van Leeuwenhoek's discovery of microorganisms in the 1670s, but its significance went unrecognized by his contemporaries. If only Leeuwenhoek or Lazzaro Spallanzani had had the pupils they deserved, Wootton writes, the crucial revolution of germ theory would have come about 150 years earlier. And why did they not have those students? Because medicine deliberately turned its back on the microscope as a threat to existing clinical practice. Throughout history, Wootton suggests, doctors have first considered their practices and incomes rather than medical progress and the interests of their patients. This, of course, is the well-recognized phenomenon of 'institutional drag', and has long been acknowledged by doctors themselves, at least in Britain. In 1929, for example, the British Medical Journal noted that "Progress marches slowly in England, for medical investigators have a full-the eager research worker may be inclined to say 'overfull'- sense of responsibility, and try the new thing only with the greatest caution" (Editorial (1929) BMJ 2: 2-3).

The idea that medicine, for most of history, was at best incompetent and at worst dangerous and destructive, is not new. As the twentieth-century US physician Lewis Thomas notoriously remarked, medical history is not popular because "it is so unrelievedly deplorable a story." Nonetheless, Wootton writes as if he is bringing to light a fact that professional historians of medicine have actively obscured. How often and how insistently universally acknowledged truths should be aired is debatable, and there is certainly more behind the story of medicine before 1860 than W ootton allows. Belief systems and technologies, knowledge and culture, observation and trust: together they make the history of medicine a complex tapestry. And pre-modern medicine was not without its skills: skeletal remains provide evidence that surgeons were adept at repairing bodies; blood-letting can be useful in reducing fever; and the therapeutic potential of many plants once used in salves and potions is now being rediscovered. The relationship between doctor and patient, trust, imagination and the placebo effect are unquantifiable. Doctors certainly did harm as well as good in the age before scientific medicine; even with the best will in the world, they might still do so today.

As it happens, Wootton's main arguments were presented and discussed-at rather less length- by David Weatherall in the introductory chapter to Science and the Q uiet Art, published in 1995. Weatherall speaks for medicine, yet his discussion seeks to explain, rather than to excuse, the fact that "until the nineteenth century medical science did not make a great impact on society." Much recent historical scholarship has shown how medical achievement comes not through the 'eureka moments' beloved of populist historians and medical mythmakers, but by the steady accumulation of small advances that either build significant progress slowly or provide essential context for a transforming realization. Weatherall knew this: "Although one area of research may be well developedHarvey's concept of the circulation, for example- unless work in related fields has led to a critical level of understanding, there will be no practical results." As Pasteur himself noted, chance favours the prepared mind. Pasteur's knowledge of chemistry, Lister's of brewing, Koch's of natural history: this information was critical to their discoveries. Even given germ theory, the early therapeutic achievements of modern medicine could not have come about without crucial parallel developments in serology and biochemistry. Weatherall's book is a disinterested recognition and discussion of the shortcomings of clinical practice, past and present.

Science and the Quiet Art is a useful and interesting companion piece to the polemical Bad Medicine. It is tempting to suggest that the experienced clinician, thoughtfully considering medical history in the light of the deficiencies he acknowledges in clinical practice, offers a valuable corrective to the historian whose only experience of medicine is as a patient and not as a practitioner.

\section{AnneH ardy is Professor in the History of Modern Medicineat University College London, UK. \\ E-mail: a.hardy@ud.ac.uk \\ doi:10.1038/sj.embor.7400864}

